\title{
RFID na edificação: proposta de modelo de sistema para organização das informações de manutenção
}

\author{
RFID in building: proposal of a system model for \\ organizing maintenance information
}

\section{Maria Aparecida Steinherz Hippert \\ Orlando Celso Longo \\ Adriano Castro Moreira}

\section{Resumo}

A indústria da construção civil é vista como uma indústria baseada no conhecimento. Ao longo do processo de projeto de uma edificação várias informações são geradas e compõem uma série de documentos que, após a conclusão da obra, devem ser entregues aos proprietários e gestores das edificações para a devida manutenção do imóvel. Essas informações devem estar organizadas de maneira a permitir seu resgate e utilização quando necessário. O uso das novas tecnologias de informação e comunicação (TIC) vem ajudar nessa organização. Entre elas se pode citar a Radio-Frequency Identification (RFID), uma tecnologia para coleta de dados automatizada que já vem sendo adotada por algumas indústrias. Este trabalho tem por objetivo propor um modelo de sistema informatizado para acesso às informações de manutenção utilizando-se das etiquetas RFID instaladas nos elementos da construção, dispositivos móveis para leitura e softwares livres a fim de reduzir os custos da implantação e operacionalização do sistema. Um experimento foi realizado a fim de validar o modelo proposto bem como demonstrar a contribuição deste para a melhoria do acesso às informações. O trabalho contribui para a discussão sobre a aplicação da tecnologia RFID associada aos dispositivos móveis na manutenção de edifícios.

Palavras-chave: Tecnologia da Informação e Comunicação (TIC). Radio-Frequency Identification (RFID). Manutenção de edifícios.

\begin{abstract}
The construction industry is seen as a knowledge-based industry. Throughout the process of designing a building, much information is generated, and it is written down in a series of documents that, upon completion of the work, must be delivered to the owners and managers of the buildings for the proper maintenance of the property. This information must be organised in such a way as to enable it to be retrieved and used where necessary. The use of new information and communication technologies (ICTs) helps in this organisation. These include the Radio-Frequency Identification (RFID) technology, an automated data collection technology that have already been adopted by some industries. This paper aims to propose a computerised system model for accessing maintenance information, using RFID tags installed in building elements, mobile reading devices and free software in order to reduce the costs of implementation and operation of the system. An experiment was carried out in order to validate the proposed model, as well as to demonstrate the contribution of the model to the improvement of access to information. This paper contributes to the discussion on the application of RFID technology associated with mobile devices to building maintenance.
\end{abstract}

${ }^{1}$ Maria Aparecida Steinherz Hippert ${ }^{1}$ Universidade Federal de J uiz de Fora J uiz de Fora - MG - Brasil https:// orcid. org/ 0000-0003-3604-0111

${ }^{2}$ Orlando Celso Longo ${ }^{2}$ Universidade Federal Fluminense Niterói - RJ - Brasil

${ }^{3}$ Adriano Castro Moreira 3Universidade Federal de J uiz de Fora J uiz de Fora - MG - Brasil

Recebido em 15/05/18 Aceito em 02/01/19

Keywords: Information and Communication Technology (ICT). Radio-Frequency Identification (RFID). Maintenance of buildings.

HIPPERT, M. A. S.; LONGO, O. C.; MOREIRA, A. C. RFID na edificação: proposta de modelo de sistema para organização 155 das informações de manutenção. Ambiente Construído, Porto Alegre, v. 19, n. 4, p. 155-173, out./ dez. 2019. ISSN 1678-8621 Associação Nacional de Tecnologia do Ambiente Construído. 


\section{Introdução}

A indústria da construção é vista como uma indústria baseada no conhecimento (ANUMBA; EGBU; CARRILO, 2005). Ao longo do processo de projeto de uma edificação várias informações são geradas e compõem uma série de documentos que, após a conclusão da obra, devem ser entregues aos proprietários e gestores das edificações. Estes últimos têm a função de organizar essas informações de maneira a subsidiar a realização das atividades de manutenção. Contudo, o aumento da complexidade das edificações fez aumentar o volume da documentação gerada. Assim, a manutenção, embora seja a fase mais onerosa do ciclo de vida da edificação, é a que mais se beneficia da informação organizada, visto que recebe várias informações relativas à edificação desde sua concepção.

No Brasil, a publicação da norma de desempenho de edificações, a NBR 15575 (ABNT, 2013), vem ressaltar a importância de se realizar a manutenção. Essa norma também estabelece a necessidade de se manterem os registros das ações de manutenção realizadas, além de atribuir incumbências aos intervenientes do processo. Para Kim et al. (2005), a avaliação de desempenho da edificação é necessária para reduzir as demandas por reconstrução ou reforma, além de servir para assegurar a longevidade dos edifícios.

O uso de tecnologias de informação e comunicação (TIC) vem ajudar na organização das informações de manutenção da edificação. A manutenção está inserida num contexto mais amplo chamado de gestão de facilities (Facilities Management - FM). Para Alexander (2003 ${ }^{1}$ apud MOTA, 2017), a FM é a forma que garante um melhor funcionamento da edificação, através de um conjunto de sistemas e processos relacionados. Ela pode ser entendida como a gestão de pessoas, espaços, processos de trabalho e investimentos inseridos em um ambiente organizacional. No âmbito da manutenção de edifícios, ela visa ao estabelecimento de diretrizes administrativas e operacionais que assegurem um perfeito funcionamento do edifício (FERREIRA, 2005). Entre as TICs existentes pode-se citar a Radio-Frequency Identification (RFID), uma tecnologia de coleta de dados automatizada que já vem sendo adotada por algumas indústrias, tais como de logística, de varejo e aeroespacial (LI; BECERIK-GERBER, 2011; VALERO; ADAN; CERRADA, 2015; TULLA et al., 2009).

${ }^{1}$ ALEXANDER, K. (Ed.). Facilities Management: theory and practice. Taylor \& Francis E-library: e \& Fn Spon, 2003.
Na construção civil, o uso do RFID não é completamente novo. Segundo Valero, Adan e Cerrada (2015), desde a década de 1990 ele tem sido aplicado no campo da construção. Porém, segundo Lu, Huang e Li (2011), o potencial de aplicação dessa tecnologia na construção civil ainda é pouco explorado. Para Lin, Cheung e Siao (2014), existe pesquisa e literatura na prática e na academia a respeito da aplicação da tecnologia RFID em algumas áreas da indústria da construção, como gestão de materiais, gestão de equipamentos, inspeção e gestão da qualidade, gestão da segurança e FM.

O trabalho com FM apresenta como uma de suas características a mobilidade. Esse aspecto faz surgir a necessidade de utilização de novas tecnologias, como smartphones, iPads e outros dispositivos móveis. Os celulares têm sido utilizados para comunicação de mensagens de texto e voz, mas, uma vez integrados aos leitores de RFID, permitem que surjam novas aplicações (TULLA et al., 2009; TOLMAN et al., 2009). Os celulares apresentam como uma de suas vantagens o fato de sua utilização já ser de domínio da maioria das pessoas.

Embora aplicações usando RFID e dispositivos móveis tenham sido identificadas na literatura, não foram encontrados sistemas desenvolvidos com base no conceito de código aberto, isto é, sem aquisição de softwares para a operacionalização do sistema. Nesse sentido, este trabalho tem por objetivo propor um modelo de sistema para a organização das informações de manutenção utilizando-se das etiquetas RFID e de dispositivos móveis para leitura. Com isso, os elementos da edificação receberão uma etiqueta através da qual será possível identificar suas informações de manutenção. Quando em operação, o sistema será capaz de fornecer as informações previamente armazenadas em um banco de dados. De maneira a tornar o sistema mais acessível e menos oneroso ele, foi proposto com base em softwares livres.

A fim de validá-lo, um experimento foi realizado. A validação teve por objetivo a análise do conceito que está sendo proposto, isto é, uso de RFID, dispositivos móveis e softwares livres para a organização das informações de manutenção. Os resultados obtidos permitiram avaliar a pertinência da aplicação proposta, bem como apresentar sugestões para futuras pesquisas. $O$ trabalho contribui para uma maior divulgação do uso de novas tecnologias para a organização das informações de manutenção de edifícios. 


\section{RFID e novas tecnologias na construção civil}

RFID é um termo genérico utilizado para descrever um sistema que usa ondas de rádio para identificação automática de pessoas e objetos. Para Li e Becerik-Gerber (2011), um sistema RFID típico é composto basicamente de dois elementos: um leitor e etiquetas de radiofrequência (tags) que operam a certa frequência. O leitor é composto de um transmissor e de uma antena, e as tags, de um microchip e de uma antena interna. As tags são fixadas em um objeto e possuem informações sobre o objeto que são enviadas ao leitor, quando requisitado.

O leitor envia um sinal a uma tag, ela é ativada e devolve o sinal ou transmite seu próprio sinal de volta ao leitor. O sinal é transmitido através de uma onda de radiofrequência na qual a tag está sintonizada para receber e devolver a informação armazenada. O leitor recebe a informação e a envia para o computador, no qual deve haver um software que interpreta os dados recebidos.

As faixas de frequência disponíveis para que o sistema RFID possa funcionar são a baixa frequência (low frequency - LF), a alta frequência (high frequency - HF), a ultra-alta frequência (ultra high frequency - UHF), micro-ondas (microwaves) e banda ultralarga (ultra-wide band - UWB) (VALERO; ADAN; CERRADA, 2015).

As tags RFID, em função do tipo de alimentação elétrica utilizado para o envio da onda, podem ser classificadas em passivas, ativas ou semipassivas (LI; BECERIK-GERBER, 2011). As tags passivas precisam ser ativadas pela energia eletromagnética emitida pelo leitor e dependem dessa energia para operar. Elas possuem intervalo de leitura mais curto e menor capacidade de armazenamento de dados. As tags ativas possuem baterias internas para o fornecimento de energia, o que melhora o intervalo de leitura bem como sua memória. Já as tags semipassivas usam baterias internas, que só são ativadas pela presença do leitor.

Para os objetivos deste trabalho uma outra tecnologia associada ao RFID deve ser destacada, a Near Field Communication (NFC). O NFC é um termo utilizado para identificar uma tecnologia de interconexão ponto a ponto sem fio de curto alcance. O NFC é padronizado pela ISO 18092/ECMA 340 (NFCIP-1), que especifica a interface e o protocolo de comunicação de fio entre dispositivos acoplados. Segundo o protocolo NFCIP-1, o NFC possui interface de operação por radiofrequência, trabalhando em 13,56 MHz e com pequenas distâncias (INTERNATIONAL..., 2013). O NFC é composto de três elementos básicos: um leitor, uma antena e uma etiqueta (tag). Ainda segundo o protocolo citado, a operação do sistema pode se dar de modo ativo, quando os dois dispositivos envolvidos na comunicação geram ondas eletromagnéticas para transportar dados, e de modo de comunicação passivo, quando um dos dispositivos gera as ondas enquanto o outro usa a modulação recebida para retransmitir dados.

Ainda no campo das novas tecnologias, cabe ressaltar o papel dos dispositivos móveis (smartphones, iPads, etc.). Vários dos modelos hoje existentes possuem câmera digital, rádio bluetooth, GPS e mesmo um leitor de NFC/RFID integrado. Quando associados às tags RFID instaladas nos objetos ou elementos, e com conexão a um sistema de TIC, fornecem maneiras rápidas de recuperar e compartilhar informações.

Alguns exemplos de aplicação do RFID na construção civil podem ser vistos em Dzeng, Lin e Hsiao (2014), que apresentam um modelo para otimização da atribuição de espaço-função a partir dos dados dos movimentos dos ocupantes rastreados por RFID. Segundo os autores, essa atribuição é um dos fatores mais importantes na determinação do desempenho da usabilidade de um edifício. Lu, Huang e Li (2011) investigam cenários para potencial aplicação do RFID na gestão do projeto de construção com o foco na gestão de materiais, homens e maquinário. Os autores concluem que o uso do RFID tem grande potencial para melhorar o tempo, a qualidade e os custos do projeto. El-Omari e Moselhi (2011) apresentam um modelo de controle da produção que integra diferentes tecnologias automatizadas de coleta de dados a um sistema de software de planejamento e programação, um banco de dados relacional e AutoCAD para gerar relatórios de progresso de maneira a auxiliar as equipes de gerenciamento de projetos na tomada de decisões. Costin, Pradhananga e Teizer (2012) propõem um sistema RFID para rastreamento de recursos em canteiro de obras que coleta e distribui a informação para os tomadores de decisão. Wang (2008) explora a aplicação da RFID para a inspeção e gestão da qualidade.

Na fabricação de componentes, Zhong et al. (2017) apresentam uma plataforma BIM multidimensional para conseguir visibilidade e rastreabilidade em tempo real na indústria de construção pré-fabricada fazendo uso da Internet das Coisas (IoT) e RFID. Altaf et al. (2018) propõem um sistema integrado de planejamento e controle para a produção de painéis de casas pré-fabricadas usando simulação, data mining e RFID. Tao et al. (2018) desenvolvem um sistema de monitoramento de emissões de gases do efeito estufa na fabricação de componentes préfabricados baseado na IoT e em RFID. 
RFID Journal Brasil (2013) relata uma aplicação com RFID para rastreamento de materiais ao longo do ciclo de vida da edificação. Ko, Azambuja e Lee (2016) também propõem um sistema de baixo custo para o rastreamento e gestão de materiais baseado em computação em nuvens e integrado com RFID para contratantes de pequeno e médio porte. Na cadeia de suprimento têm-se ainda os trabalhos de Demiralp, Guven e Ergen (2012), que propõem uma divisão dos custos entre os agentes da cadeia de suprimento da construção em função dos benefícios recebidos a partir do rastreamento dos componentes usando RFID, e de Hinkka e Tätilä (2013), que apresentam um modelo de implementação de rastreamento para o comércio técnico e indústria da construção usando RFID.

Na segurança do trabalho em canteiro de obras, Kelm et al. (2013) propõem um portal móvel utilizando RFID para controle automatizado de equipamentos de proteção individual (EPIs), enquanto Oliveira e Serra (2017) apresentam um sistema de monitoramento e controle remoto de equipamentos de proteção coletiva (EPC) utilizando RFID. Valero, Adan e Cerrada (2015) fazem uma revisão da literatura sobre a aplicação do RFID não somente para gestão de materiais e monitoramento de canteiro, como no trabalho de Lu, Huang e $\mathrm{Li}$ (2011), mas também nas fases antes e depois da construção, isto é, planejamento, projeto e manutenção. Para a manutenção, Ko (2009) estabelece um sistema utilizando RFID integrado à internet com módulo de gerenciamento de dados, análise estatística e programação das atividades de manutenção. Os usuários são autorizados a realizar as tarefas de manutenção através do sistema baseado na web. Li, Calis e Becerik-Gerber (2012) propõem um sistema baseado em RFID para detecção de ocupação, de maneira a suportar operações de sistemas de aquecimento, ventilação e aquecimento de ar (HVAC) sob demanda, detectando e rastreando múltiplos ocupantes fixos e móveis em múltiplos espaços simultaneamente. Li e Becerik-Gerber (2011) apresentam um levantamento de 39 projetos de pesquisa e estudos de casos referentes à aplicação da RFID no ciclo de vida da edificação: pré-fabricação, construção e gerenciamento de FM. Os autores verificam que, comparativamente às outras fases, a aplicação da tecnologia RFID na FM é a menos explorada. Mais recentemente, Wong, Ge e He (2018) fazem uma revisão da literatura sobre a aplicação de tecnologias digitais, incluindo RFID, na FM.

Segundo Tulla et al. (2009), os aplicativos de manutenção provavelmente servirão para lançar e impulsionar a RFID na construção civil e na FM. Para Ergen et al. (2007), a tecnologia RFID aplicada à FM vem resolver alguns problemas como a dificuldade de resgate do histórico da manutenção de componentes, bem como os atrasos no atendimento aos problemas de operação e manutenção. Já para Ko (2017), ela vem contribuir para a redução dos custos de gestão e mesmo de geração de papéis. $\mathrm{O}$ autor apresenta diretrizes para uso do RFID em relação à distância entre o aparelho de leitura e as etiquetas em diferentes superfícies.

Aplicações usando RFID associada com o telefone celular podem ser vistas no trabalho de Lin, Cheung e Siao (2014), que apresentam um sistema para melhorar a gestão da manutenção de equipamentos e instrumentos de um laboratório de construção. Na área de FM, Tulla et al. (2009) destacam que os benefícios dessas aplicações residem, além de no tempo e na economia de custos, no potencial para melhoria dos serviços a partir da comunicação com os clientes. Para Tolman et al. (2009), os usos mais comuns para as tecnologias integradas aos dispositivos móveis incluem o gerenciamento de solicitações de serviços, o controle da qualidade, o gerenciamento de ativos fixos (equipamentos, máquinas e veículos, etc.) e o controle da logística, além de gestão das informações (relatórios, consultas e transmissão de informações). Segundo Valero, Adan e Cerrada (2015), o uso de RFID associado com dispositivos móveis e sem fio é uma tendência de mercado.

O uso das tags RFID associadas com dispositivos móveis, conforme mencionado, demanda um software que seja capaz de acessar, interpretar e/ou gravar conteúdos nas tags. Na presente proposta faz-se uso da cultura de código aberto (open source). Segundo Tolman et al. (2009) ele é emergente para a automação da construção, bem como para a elaboração de manuais de manutenção integrados e interoperáveis. O conceito de código aberto surge do ideal de distribuição livre e gratuita, com a possibilidade de utilização e/ou modificação de suas partes, desde que seja dado o crédito ao autor original (KATZ, 2011).

Em outra direção, Xue et al. (2018) propõem um modelo conceitual de ligação de RFID ao Building Information Modeling (BIM) para atividades de construção e manutenção a partir da análise de 42 estudos de caso identificados na literatura. Ao final os autores estabelecem diretrizes práticas, em cinco etapas, para a escolha do sistema RFID - BIM mais adequado às necessidades de construção e manutenção.

Apesar das características atrativas da tecnologia RFID, alguns obstáculos ainda precisam ser vencidos para uma utilização mais efetiva dela. $\mathrm{Lu}$, Huang e Li (2011) e Lin, Cheung e Siao (2014) citam o preço das etiquetas, que, entretanto, vem diminuindo a cada ano. Além disso, falta ainda 
padronização para a troca de informações (TULLA et al., 2009; LU; HUANG; LI, 2011). Tolman et al. (2009) e Li e Becerik-Gerber (2011) destacam ainda a falta de interoperabilidade e de integração entre os aplicativos móveis e os sistemas existentes na empresa, o que pode levar à redução dos potenciais benefícios para sua utilização. Wong, Ge e He (2018) também destacam a falta de interoperabilidade entre os sistemas, bem como a necessidade de melhoria da capacidade de armazenamento e gerenciamento de dados baseados em RFID.

\section{Manutenção de edifícios}

Um projeto de construção civil, por sua própria natureza, é dinâmico e apresenta como principal característica seu ciclo de vida, identificado por uma data de início e outra de término e por um conjunto de fases intermediárias altamente interdependentes.

Enquanto a maioria das fases pode ser considerada de curta duração relativa, a fase de uso, de longa duração, é aquela em que são realizadas as atividades de operação e manutenção (O\&M) da edificação. Elas se referem à realização de trabalhos visando à manutenção, ao restauro e ao melhoramento de todas as partes, subsistemas, serviços e arredores de um edifício a fim de sustentar sua utilidade e valor (EL-HARAM; HORNER, 2002).

Embora a manutenção seja executada somente na fase de uso, ela deve ser pensada desde seu início. A não consideração da manutenção no início do projeto tem sido responsável por uma série de problemas identificados na edificação após sua conclusão (SANCHES; FABRÍCIO, 2009; MELO FILHO; RABBANIB; BARKOKEBAS JUNIOR, 2012). A manutenção é importante para prolongar a vida útil da edificação. Quanto mais tarde ela for iniciada, maior será seu custo e maior o comprometimento do desempenho da edificação (ABNT, 2013).

A realização da manutenção exige a integração de diferentes informações criadas por diferentes intervenientes, tais como registros de manutenção, ordens de serviço, causas e efeitos de falhas, etc. A falha em capturar e usar essas informações/conhecimento resulta em custos significativos devido a decisões ineficazes (MOTAWA; ALMARSHAD, 2013). De maneira a regulamentar as atividades de manutenção, normas técnicas têm sido estabelecidas. Em âmbito internacional, Gonçalves (2014) apresenta as principais referências portuguesas e europeias que estabelecem regras, requisitos e procedimentos de manutenção, como os Critérios para a concepção, gestão e controle de serviços de manutenção para edifícios (EN 15331) e o Sistema de gestão da manutenção. Requisitos para a implementação do sistema de gestão da manutenção (NP 4483). No Brasil, as normas de manutenção publicadas pela ABNT são a NBR 5674 - Manutenção de edificações - Requisitos para o sistema de gestão da manutenção (ABNT, 2012) e a NBR 14037 Manual de operação, uso e manutenção das edificações - Conteúdo e recomendações para elaboração e apresentação (ABNT, 2011).

A NBR 5674 (ABNT, 2012) estabelece que o serviço de manutenção deva ser realizado por pessoal habilitado, seja uma equipe de manutenção local, uma empresa capacitada e/ou uma empresa especializada. Os primeiros realizam serviços diversos para os quais tenham recebido orientação. A empresa capacitada é a organização ou pessoa que tenha recebido capacitação e trabalhe sobre a responsabilidade de profissional habilitado. Por fim, a empresa especializada é a organização ou profissional liberal que realiza trabalho para os quais são exigidas qualificações específicas. Essa norma estabelece ainda a necessidade de elaboração de um programa de manutenção, que deve conter uma série de documentos que orientem a execução das atividades de manutenção, bem como os registros das intervenções realizadas (Quadro 1).

O manual de uso, operação e manutenção, cujo conteúdo está disposto na NBR 14037 (ABNT, 2011), tem por finalidade informar as características técnicas do imóvel, descrever procedimentos recomendáveis para o melhor aproveitamento da edificação, orientar a realização das atividades de manutenção, prevenir a ocorrência de falhas e acidentes decorrentes de uso inadequado e contribuir para o aumento da durabilidade da edificação. 


\section{Quadro 1 - Programa de manutenção}

\begin{tabular}{|l|}
\hline DOCUMENTOS \\
\hline Manual de uso, operação e manutenção das edificações conforme a NBR 14037 (ABNT, 2011) \\
\hline Manual dos fornecedores dos equipamentos e serviços \\
\hline Programa da manutenção \\
\hline Planejamento da manutenção contendo o previsto e o efetivo \\
\hline Contratos firmados \\
\hline $\begin{array}{l}\text { Catálogos, memoriais executivos, projetos, desenhos, procedimentos executivos dos serviços de } \\
\text { manutenção e propostas técnicas }\end{array}$ \\
\hline $\begin{array}{l}\text { Documentos mencionados na NBR 14037, Anexo A, constando a qualificação do responsável e os } \\
\text { comprovantes de renovação }\end{array}$ \\
\hline Documentos de atribuição de responsabilidade de serviços técnicos \\
\hline REGISTROS \\
\hline Relatório de inspeção \\
\hline Registros dos serviços de manutenção realizados \\
\hline Atas das reuniões de assuntos relativos à manutenção \\
\hline
\end{tabular}

Fonte: adaptado da NBR 5674 (ABNT, 2012).

Além de atender às normas de manutenção, o manual deve contemplar ainda as exigências da norma brasileira de desempenho das edificações, a NBR 15575. Esta norma estabelece requisitos e critérios de desempenho aplicáveis às edificações habitacionais de forma integrada, ou a seus sistemas componentes. Ela é dividida em seis partes, referentes ao sistema estrutural, sistema de piso, sistema de vedação vertical, sistema de cobertura e sistema hidrossanitário. Os requisitos dispostos na norma referem-se a segurança, habitabilidade e sustentabilidade. Este último inclui os requisitos relativos à manutenibilidade, que, de maneira geral, remetem à necessidade de prover condições de fácil acesso para a realização das inspeções e análise do manual de uso, operação e manutenção. A dificuldade de acesso para a manutenção de instalações é apontada por autores como Melo Filho, Rabbanib, Barkokebas (2012), Gnipper (2010) e Sanches e Fabrício (2009).

Com relação aos fornecedores, o programa de manutenção deve conter os contratos firmados e os manuais dos equipamentos fornecidos ao condomínio, quando de sua instalação, bem como dos serviços prestados. As empresas/profissionais que realizam a manutenção devem fornecer catálogos, memoriais executivos, projetos, desenhos e procedimentos executivos dos serviços de manutenção prestados, bem como suas propostas técnicas.

Ainda com relação à documentação, devem ser considerados aqueles referentes à atribuição de responsabilidades pelos serviços, bem como os mencionados no Anexo A da NBR 14037 (ABNT, 2011), que são específicos para a edificação, tais como auto de conclusão (habite-se), alvará de aprovação e execução de edificação, projetos (incluindo projeto as-built), etc. Para Klein, Li e Becerik-Gerber (2012), os projetos as-built são essenciais para as atividades de O\&M das edificações e precisam ser continuamente verificados e atualizados. Nesse sentido, os autores investigam as vantagens e limitações de uso do processamento fotogramétrico de imagens para documentar e verificar as condições atuais da edificação. O programa de manutenção deve ainda conter um planejamento da manutenção contendo o previsto e o realizado.

Enquanto os documentos servem para orientar a realização das atividades de manutenção, os registros servem para atestar que o programa de manutenção foi efetivamente implementado, e também que foram realizados o planejamento, as inspeções e as atividades de manutenção. São exemplos de registros dos serviços executados os laudos ART e termo de garantia.

Segundo a NBR 5674, no caso de edificações condominiais, os condôminos respondem individualmente pela manutenção das partes autônomas e solidariamente pelas áreas comuns da edificação. Ao síndico cabe a gestão da manutenção das áreas comuns, o qual pode delegar essa função a empresa ou profissional contratado.

Essa norma considera ainda que a gestão do sistema de manutenção deve ser orientada por um conjunto de diretrizes que estabeleça, entre outras, as informações pertinentes e o fluxo da comunicação. Dessa forma, a estruturação de um sistema de gestão da manutenção demanda a organização das informações de manutenção de maneira que elas possam ser recuperadas quando se fizer necessária sua utilização. Quanto às informações, Lee e Akin (2009) levantaram as práticas atuais em O\&M, desde a fase inicial de atribuição de solicitações de 
manutenção até a conclusão, a fim de identificar tipos de ineficiência e suas causas. Os autores concluem que os profissionais de manutenção subutilizam os dados de manutenção no campo devido a problemas com acessibilidade e confiabilidade desses dados. Já Xua et al. (2018) propõem uma gestão integrada da informação estruturada de defeitos superficiais em edifícios compatível com um modelo de nuvens de pontos como fonte. Os resultados analíticos mostram que o método proposto funciona bem para resolver o problema de classificação multiatributo dos defeitos de construção e para evitar respostas ambíguas. Motawa e Almarshad (2013) apresentam um sistema integrado para captura de informações e conhecimento das operações de manutenção do edifício após realizadas para entender como um edifício está se deteriorando e para apoiar decisões de manutenção preventiva ou corretiva. Quanto à comunicação, Au-Yong, Ali e Ahmad (2014) investigam as características de manutenção do sistema HVAC de edifícios de escritórios, que afetam a satisfação dos ocupantes, e concluem que o desenvolvimento de uma plataforma que promova uma comunicação eficaz entre os participanteschave das atividades de manutenção é necessária para melhorar os resultados de manutenção.

A utilização do BIM nas atividades de O\&M começa a surgir. Lu et al. (2018) apresentam um modelo de sistema de atividade analítica (ASM) utilizando a teoria da atividade para analisar o uso do BIM na construção de O\&M de forma sistemática e dinâmica. O BIM pode contribuir para otimizar a manutenção e a FM, exportando as informações da edificação e de equipamentos para o sistema que será usado ao longo do ciclo de vida da instalação (EASTMAN et al., 2011). Pärna, Edwardsa e Sing (2017) fazem uma revisão da literatura sobre padrões que impactam no BIM e sua aplicação na FM durante a fase de O\&M do edifício. Shen, Hao e Xue (2012) apresentam uma abordagem de integração de sistemas para suporte à decisão na manutenção e FM baseada em BIM e RFID. Para situações de emergência, Li et al. (2014) introduziram um algoritmo de localização interna centrado em BIM para localizar os primeiros socorristas e ocupantes presos em situação de incêndio em edifícios.

As informações de O\&M são tradicionalmente fornecidas de forma não estruturada ao final da construção, mas essa situação começa a mudar com a entrada do padrão Construction-Operation Building Information Exchange (COBie). Segundo Eastman et al. (2011) o COBIe caracteriza e estrutura a informação de maneira prática e fácil de ser implementada, e delineia um método padrão para colecionar a informação durante o processo de projeto e construção, como parte do pacote a ser entregue ao proprietário da edificação.

No Brasil, é ainda pequeno o número de empresas que utilizam BIM em suas rotinas de trabalho (MINISTÉRIO..., 2018). Contudo, esse cenário deve se alterar com a instituição pelo governo federal brasileiro da Estratégia Nacional para Disseminação do BIM (BRASIL, 2018), com o intuito de aumentar a produtividade das empresas do setor e reduzir os custos de suas obras.

Por outro lado, o BIM vem sendo utilizado, de maneira geral, para os novos edifícios, sendo sua implementação ainda escassa em edificações existentes (WONG; GE; HE, 2018; VOLK; STENGEL; SCHULTMANN, 2014). Chen et al. (2018) desenvolvem uma estrutura de planejamento de varredura proativa automática que poderia gerar um plano de varredura com base em determinado leiaute de edifício e em requisitos de qualidade de nuvem de pontos. Para Wong, Ge e He (2018), o uso do BIM nas edificações existentes requer estudos para melhorar o processo de captura de dados, interoperabilidade e padrões para BIM-FM.

\section{Método}

\section{Considerações iniciais}

Ao longo do ciclo de vida de uma edificação (concepção, planejamento, execução e manutenção) são geradas várias informações. Para Cintra (2005), é necessária uma melhor integração e compartilhamento da informação entre os diversos atores envolvidos no processo de construção como forma de contribuir para seu sucesso. A falta de informação, ou informação insuficiente, pode levar a uma série de problemas nas etapas desse processo.

No Brasil, para as edificações habitacionais, na entrega da obra o incorporador/construtor deve apresentar ao gestor (síndico ou empresa contratada) uma série de documentos contendo informações que serão usadas para apoiar a realização da manutenção.

Os documentos recebidos, junto com os registros gerados pela realização da manutenção, podem ser associados aos elementos da construção, o que permite a construção de um histórico das intervenções realizadas para cada um desses elementos. De maneira a atender à NBR 15575, esses elementos podem referir-se àqueles presentes nos sistemas de estrutura, sistemas de piso, sistemas de vedação vertical, sistemas de cobertura e sistemas hidrossanitários da edificação.

Nesse cenário faz-se necessário o uso de TICs de maneira a apoiar a realização da atividade pretendida. Assim, é proposta a utilização de tags 
RFID instaladas nos elementos da construção passíveis de manutenção e uso de dispositivos móveis (smartphones) para leitura delas. Para o funcionamento desse arranjo, é feita uma adaptação da proposta de Moreira (2017), que criou um modelo para rastreabilidade das informações de construção usando as etiquetas QR Code associadas aos softwares livres e/ou de códigos abertos. No entanto, a presente proposta faz uso das etiquetas RFID, que apresentam melhor resistência ao desgaste quando expostas ao ambiente em comparação às etiquetas QR Code. Além disso, não precisam estar visíveis para que a leitura ocorra, mas localizadas ao alcance do dispositivo de leitura.

\section{Método de pesquisa}

O método de pesquisa adotado para a realização do trabalho foi a Design Science Research (DSR). Segundo Dresch, Lacerda e Antunes Junior (2015), ela é indicada quando os objetivos a ser alcançados são produzir artefatos com o fim de solucionar problemas do mundo real e, ao mesmo tempo, contribuir para o conhecimento da área na qual se está trabalhando. Ainda segundo os autores, a DSR tem como característica fundamental ser orientada à solução de problemas específicos. Não necessariamente se busca a solução ótima, mas aquela que atenda de maneira satisfatória à situação estudada. Porém, as soluções geradas devem ser passíveis de generalização, de maneira que outros pesquisadores e profissionais, em situações diversas, também possam fazer uso do conhecimento gerado.

Dessa forma, a partir das necessidades observadas, a DSR pode apoiar o desenvolvimento e a construção de artefatos e, ao mesmo tempo, contribuir para o aumento da base de conhecimento de determinada área (DRESCH; LACERDA; ANTUNES JUNIOR, 2015).

O método utilizado para operacionalizar a pesquisa em DSR foi o proposto por Takeda et al. (1990). Ele foi criado para a construção de um modelo computacional para apoio ao desenvolvimento de sistemas inteligentes de computer-aided design (CAD). O método é composto de cinco etapas, consciência do problema, sugestão, desenvolvimento, avaliação e conclusão, e está representado na Figura 1.

A primeira etapa, de conscientização, corresponde a tomar um problema por meio da comparação do objeto de estudo com suas especificações. Na presente proposta, o problema refere-se à grande quantidade de informações de manutenção dos elementos de construção presentes nas áreas comuns de uma edificação habitacional. É necessário organizá-las de maneira a se ter um acesso mais rápido às condições dos elementos, a sua necessidade de manutenção e ao histórico das intervenções realizadas.

A segunda etapa, denominada sugestão, tem por objetivo sugerir os principais conceitos que possam auxiliar o pesquisador a resolver o problema em que está debruçado. Como dito anteriormente, é proposto um modelo adaptado da proposta de Moreira (2017).

$\mathrm{Na}$ terceira etapa, de desenvolvimento, o pesquisador desenvolve possíveis soluções para o problema a partir dos conceitos anteriormente definidos. A quarta etapa, avaliação, tem por objetivo avaliar de maneira criteriosa o artefato produzido.

Figura 1 - Método utilizado para a pesquisa em DSR

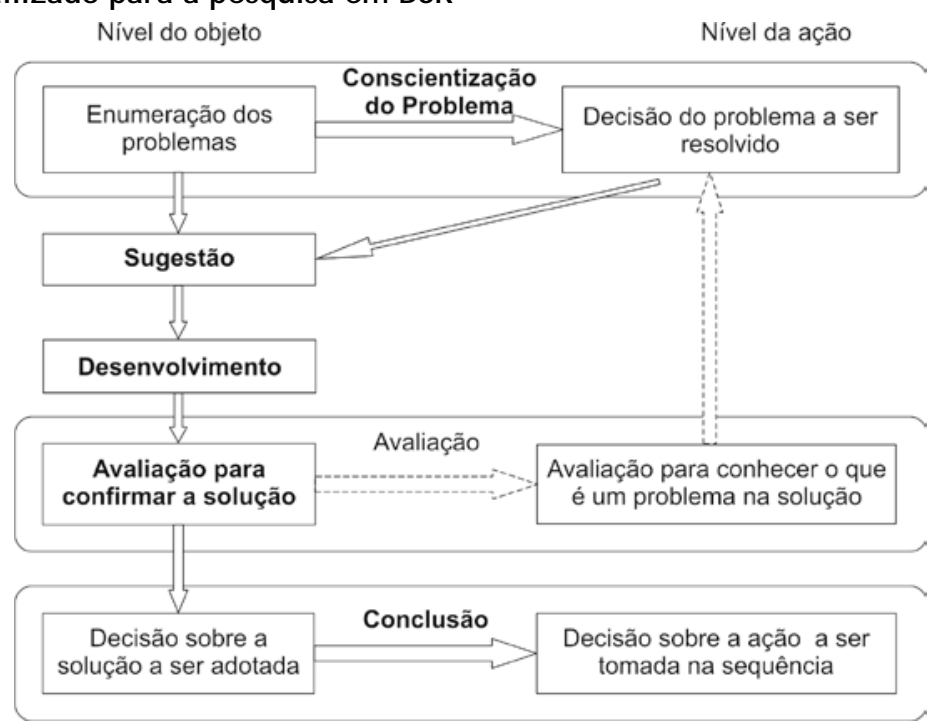

Fonte: adaptado de Takeda et al. (1990). 
Na quinta e última etapa o pesquisador deve decidir qual dos artefatos desenvolvidos apresenta o melhor resultado para o problema em questão e deverá ser adotado. Os autores ressaltam que cada ciclo atende à resolução de somente um problema, porém novos problemas podem ser encontrados durante a aplicação do método e deverão ser estudados em um novo ciclo.

Este estudo considera, a partir da necessidade de organização das informações de manutenção, de maneira a facilitar sua utilização (consciência do problema, contexto no qual se está atuando), o desenvolvimento de um sistema que integra etiquetas RFID, dispositivos móveis para leitura e softwares livres (sugestão, com adaptação da proposta de Moreira (2017) e desenvolvimento), cujos resultados são analisados quanto à validade do sistema proposto (avaliação e conclusão), contribuindo para o conhecimento sobre o uso do RFID na manutenção.

\section{Delineamento da pesquisa}

A partir da identificação da necessidade de organização da informação de manutenção e de posse do ambiente proposto por Moreira (2017), foram realizadas as adaptações necessárias de maneira a se atingir o objetivo pretendido. O ambiente foi configurado e, na sequência, foram definidas as informações a serem inseridas no banco de dados. Foi escolhida uma edificação para a realização de um experimento e levantadas suas informações. Em seguida, foram definidas as informações referentes aos elementos da construção a ser visualizadas quando do acesso às tags. Estas foram gravadas e fixadas nos elementos da construção. Realizadas as leituras, foi possível analisar os resultados obtidos (Figura 2).

\section{Desenvolvimento da proposta}

\section{Configuração do sistema}

A Figura 3 apresenta a estrutura proposta para o sistema. A configuração pode ser realizada de forma local ou remota. Para o acesso local, o servidor deverá ser instalado e configurado na edificação; neste caso, com conexão à rede lógica do prédio (destaque A na Figura 3). Para o acesso remoto, o servidor poderá ser configurado em servidor virtual na nuvem, ou ser instalado e configurado na sede da empresa responsável pela gestão da manutenção. Para isso necessita de conexão à rede internet.

A estrutura proposta compõe-se de um sistema operacional em modo servidor de rede que hospeda um servidor de banco de dados e um servidor web (que provê suporte ao framework/Content Management System - CMS), interfaceados por um navegador web. Foi criado um domínio associado a um IP (Internet Protocol) de maneira que o servidor pudesse ser localizado remotamente via internet. Além disso, é necessário também um computador com navegador web com acesso a internet para a configuração do CMS e alimentação do sistema. A especificação do equipamento deve ser feita em função dos requisitos descritos nas especificações dos softwares utilizados no ambiente, bem como na quantidade de informações que se deseja armazenar no sistema. A especificação dos elementos utilizados está no Quadro 2.

O processo de implantação do sistema está apresentado na Figura 4. A configuração do servidor de banco de dados permite a utilização de bases de dados distintas. Isso se mostra necessário no caso de o sistema ser modelado para ser utilizado por uma empresa responsável pela gestão da manutenção de várias edificações. Nesse caso, cada edificação terá sua própria base de dados.

O CMS, por sua vez, possui duas interfaces, uma para acesso do administrador (responsável pela alimentação do sistema) (destaque A na Figura 4) e outra para acesso do usuário registrado, conforme nível de permissão atribuído pelo administrador (síndico e usuários/moradores) (destaque B na Figura 4). A configuração utilizada permite que o acesso dos usuários registrados ocorra de forma simultânea. O acesso administrador é criado pelo responsável pela configuração do CMS quando da implantação do sistema e, após configurado, é entregue àquele que irá fazer sua gestão com a inclusão e organização de novos usuários e conteúdo. A atribuição de níveis de acesso está apresentada na Figura 5.

Ao administrador cabe configurar e manter o sistema, ao síndico acompanhar as informações cadastradas com possibilidade de edição delas, e ao usuário é permitida a visualização das informações, sem, entretanto, poder modificá-las.

Após implantado o sistema, o acesso às informações poderá ser realizado através da leitura da tag, por um dispositivo móvel, ou diretamente no sistema, através de um endereço web. Se o acesso ocorrer através da leitura da tag, as informações do elemento da construção serão exibidas na tela do dispositivo móvel utilizado para leitura. Se o acesso for realizado por um endereço de web (link direto), o leitor é encaminhado à página inicial do sistema e consegue navegar a partir daí até obter a informação desejada. Em ambas as situações, o acesso ocorrerá através de login e senha, em função dos níveis de autorização criados para os acessos: administrador, síndico e usuário/moradores da edificação. 
Figura 2 - Delineamento da pesquisa

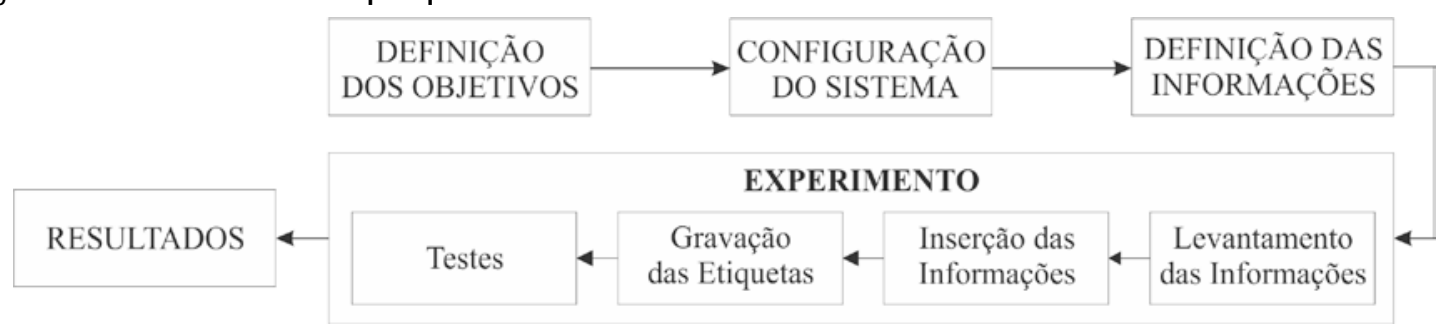

Figura 3 - Estrutura do ambiente proposto

Fonte: adaptado de Moreira (2017).

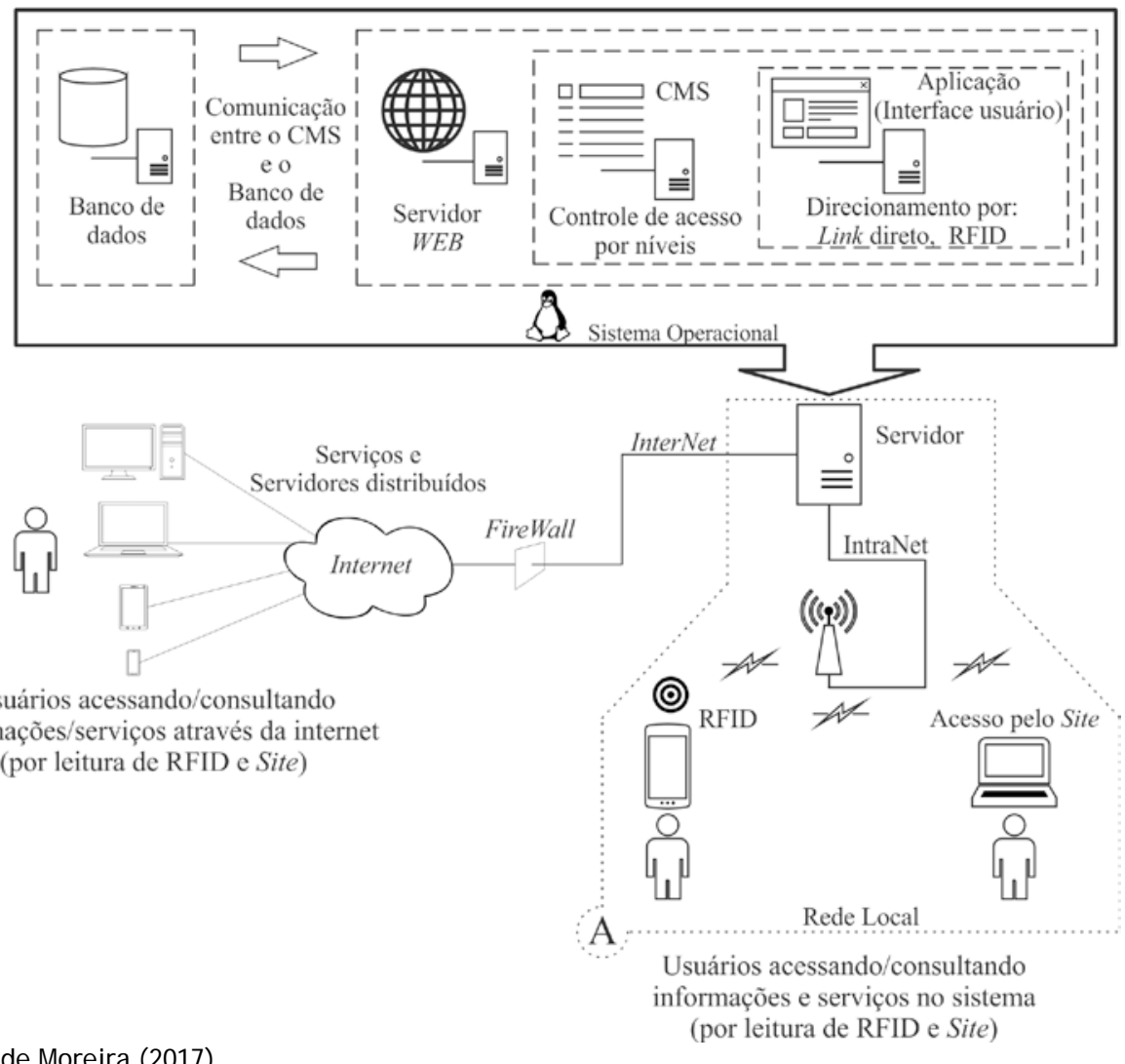

Quadro 2 - Especificação dos elementos do sistema

\begin{tabular}{|l|l|}
\hline \multicolumn{1}{|c|}{ Elemento } & \multicolumn{1}{c|}{ Especificação } \\
\hline Servidor & $\begin{array}{l}\text { Computador Dell PowerEdge 2600 Server, com seis discos de 36 Gb de } \\
\text { armazenamento em raid 5. Já vem com uma placa de rede instalada, o que } \\
\text { permite configurá-lo em rede. }\end{array}$ \\
\hline Sistema Operacional & Distribuição DEBIAN 9 do sistema operacional LINUX \\
\hline Banco de Dados & PostgreSQL \\
\hline Servidor Web & Servidor Apache \\
\hline CMS & Distribuição Joomla versão 3.8.6 \\
\hline Smartphone & Sony Xperia M com distribuição CyanoGem Mod 6 - Android \\
\hline $\begin{array}{l}\text { Aplicativo para leitura e } \\
\text { gravação das tags }\end{array}$ & NFC Tools e o NFC Task em suas versões free da empresa WakDev \\
\hline Navegador & Mozilla Firefox versão 59.0.2. \\
\hline Tag & $\begin{array}{l}\text { Passiva, modelo ISO 14443-3A, com capacidade de armazenamento de } 1 \\
\text { kbyte, frequência de 13,56 MHz na dimensão 5,4x8,6 cm }\end{array}$ \\
\hline
\end{tabular}


Figura 4 - Processo de implantação do sistema

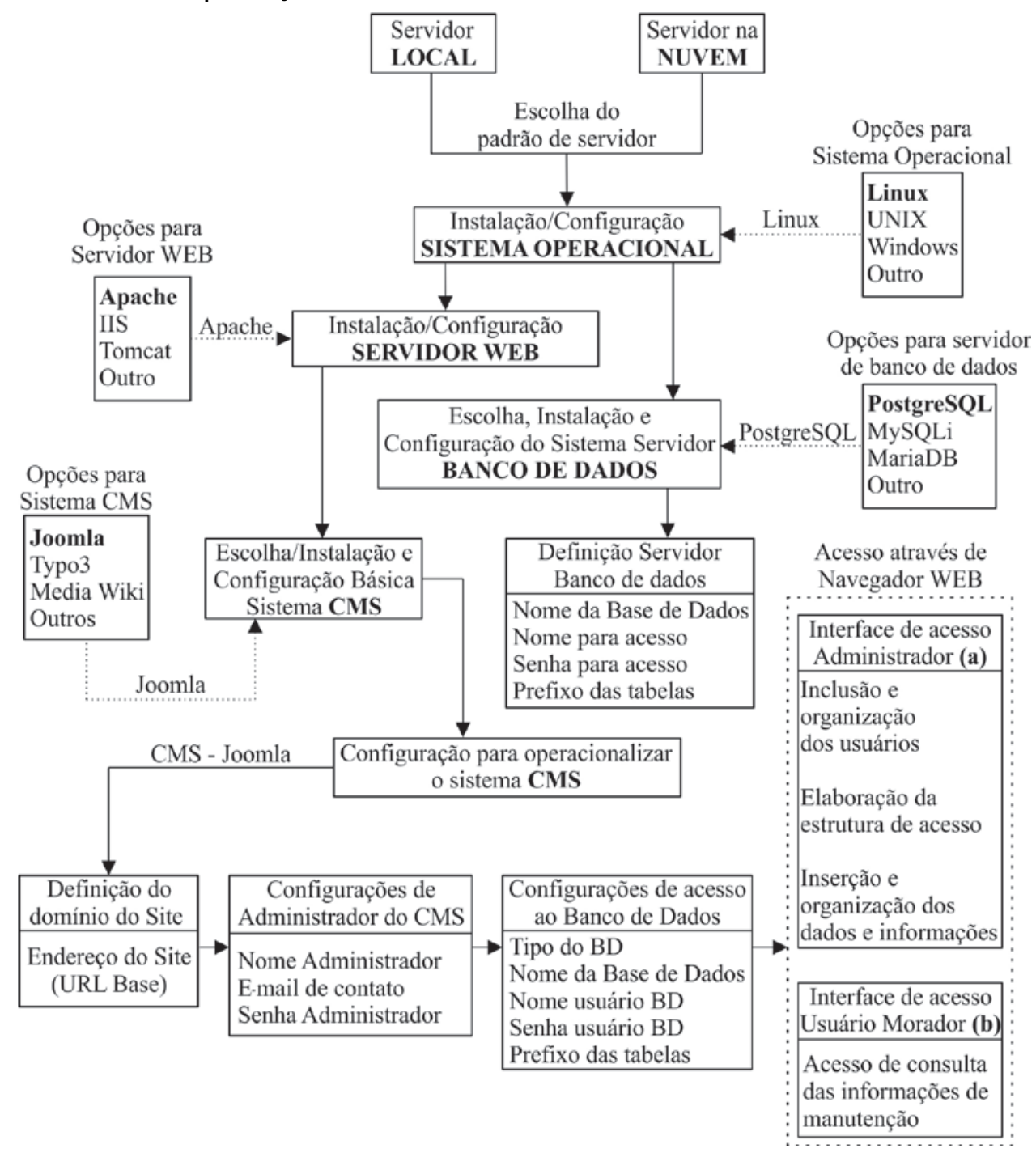

\section{Estrutura de acesso ao conteúdo}

O ambiente do CMS permite a criação de artigos de conteúdo (documentos/registros), que estão organizados utilizando-se de categorias sob uma estrutura de Menu, Itens de Menu e Artigos para que possam ser exibidos como páginas web.

Tendo em vista a necessidade de organização das informações de manutenção, a estrutura criada no CMS considerou no menu principal três itens de menu: Documentos, Registros e Elemento da Construção.

Para a realização dos testes foi atribuído a cada um desses itens uma lista de títulos organizada por Categorias. A lista de documentos e registros foi baseada na listagem presente no Quadro 1, anteriormente apresentado. Para os elementos da construção foi criada uma lista com os elementos presentes na NBR 15575: Estrutura, Piso, Vedação Vertical, Cobertura e Instalação Hidrossanitária.
Entretanto, como nas listas anteriores, novos elementos ou mesmo uma subdivisão deles podem ser inseridos. Assim, o elemento Fachada foi subdividido em fachada frontal, posterior e lateral. Um exemplo de acesso ao conteúdo é apresentado na Figura 6. Porém, cabe ressaltar que o sistema não foi alimentado com todas as informações de manutenção, mas somente aquelas necessárias a demonstrar a aplicabilidade dele.

\section{Inserção e organização dos dados e informações}

Os documentos e registros a serem utilizados para alimentação do sistema precisam estar em formato digital. Esses artigos comportam a inclusão de mídias de variados formatos, tais como $\mathrm{xml}, \mathrm{pdf}$, jpg, png, etc., que deverão ser armazenadas através de upload em diretórios do servidor, dentro do CMS. 
Figura 5 - Configuração e montagem da estrutura de usuários e conteúdo de acesso - Interface Administrador

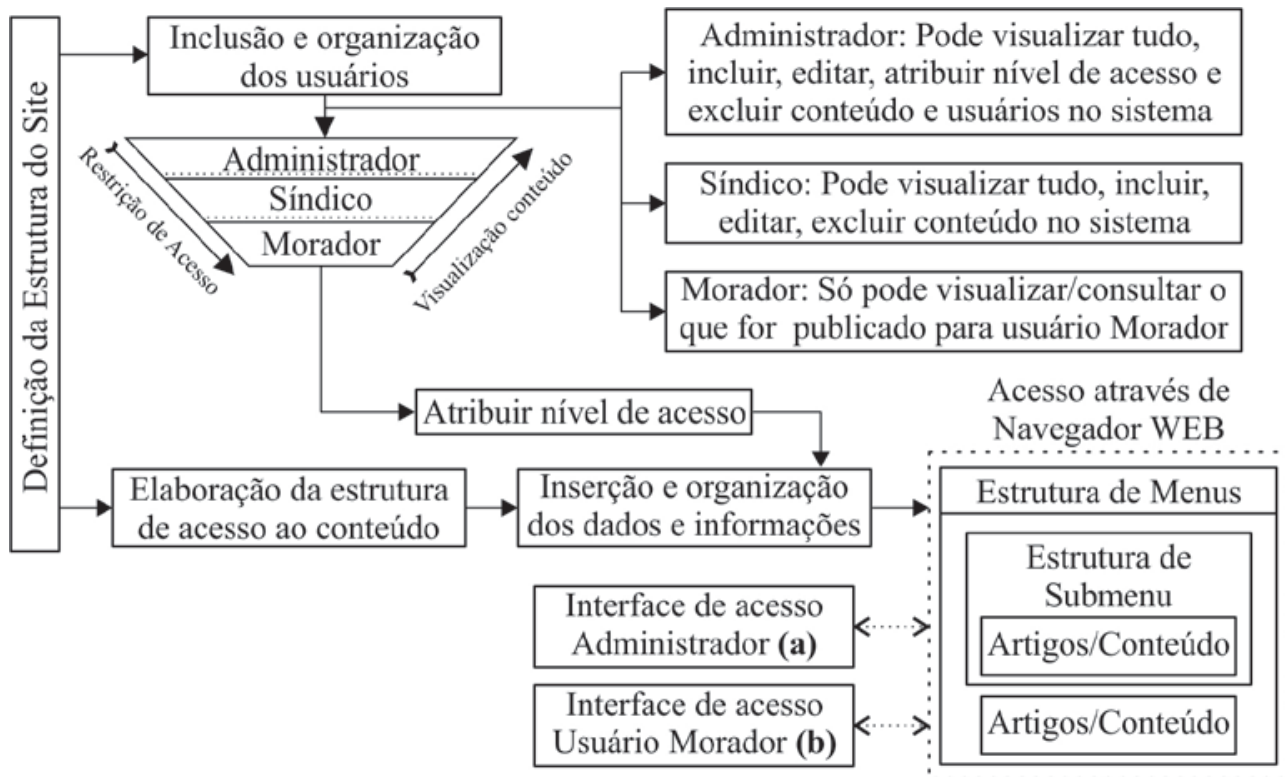

Figura 6 - Exemplo de acesso ao conteúdo

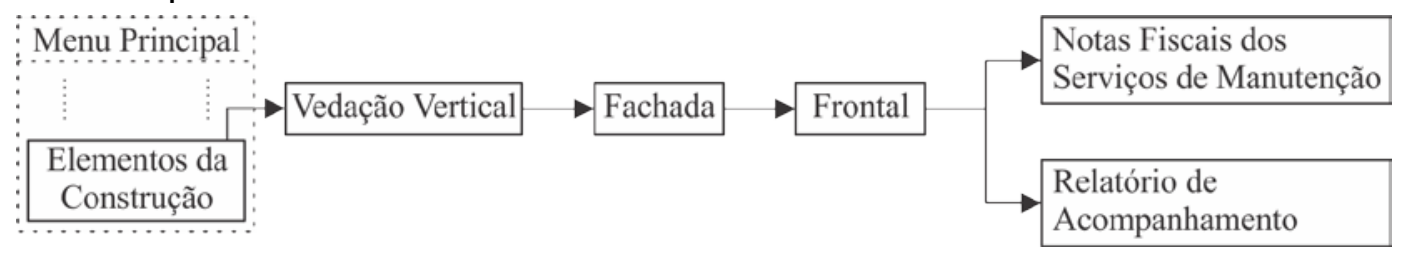

\section{Experimento}

Para a realização dos testes, foi escolhida uma edificação multifamiliar com 17 pavimentos, construída nos anos 90 no centro de uma cidade de médio porte. O servidor foi instalado no laboratório da universidade, com acesso remoto. O objeto de estudo foram as fachadas, por demandarem um serviço de manutenção especializado. O revestimento da fachada principal é composto de placas de mármore, cortina de vidro e pintura, enquanto as fachadas laterais e posterior possuem acabamento em pintura sobre argamassa.

Os projetos estão em formato 2D e não foram atualizados ao longo dos anos. O condomínio trabalha com os documentos fiscais originais em papel e todo o arquivo está organizado em caixas em uma sala junto ao playground. Alguns documentos estão arquivados em pastas com identificação do assunto, como, por exemplo, Escritura, Projeto, etc. Documentos referentes ao movimento do condomínio, isto é, contas, notas fiscais, recibos, etc., estão organizados por data, compondo as pastas de balancetes mensais.

Em um período mais recente, o síndico passou a fazer o controle dos serviços de manutenção em uma planilha eletrônica em seu computador pessoal. O síndico precisa fazer consultas frequentes ao documento a fim de obter as informações necessárias às atividades de manutenção da edificação. Até a redação deste artigo não existia um histórico formalizado dos serviços de manutenção realizados.

A manutenção da fachada do edifício tem sido realizada há algum tempo por uma mesma empresa. De posse dessa informação foi solicitada à administradora do condomínio uma relação dos pagamentos efetuados a essa empresa, tendo sido obtida uma lista contendo os serviços de fachada e de piso (também realizados pela empresa).

A partir daí foi possível organizar os serviços de manutenção de fachada em um relatório de acompanhamento e buscadas as notas fiscais relativas aos últimos anos nos arquivos em papel nas pastas de balancetes mensais. Com isso, foram dois os títulos de arquivos inseridos no sistema seguindo a estrutura apresentada na Figura 6 anterior a partir do item do menu principal Elementos da Construção:

(a) notas fiscais dos serviços de manutenção realizados; e 
(b) relatório de acompanhamento dos serviços de manutenção realizados.

As notas fiscais foram digitalizadas e realizado o upload dos arquivos no sistema. A planilha do relatório foi montada no editor do próprio CMS (Figura 7). Os arquivos foram associados aos títulos dos artigos criados na estrutura. A cada página criada anteriormente foi associada uma URL (Uniform Resource Locator). Esta pode também ser criada para os itens e subitens de menu. Essa URL é que deverá ser gravada na RFID de maneira a direcionar o usuário quando da leitura da tag. É possível ser direcionado a um nível mais geral, como, por exemplo, Elemento Vedação Vertical, e a partir daí o usuário selecionar a opção desejada (subdivisões do Elemento) ou ser encaminhado diretamente a um nível mais específico de subdivisão do elemento, como, por exemplo, Fachada Frontal. Para a realização dos testes foram gravadas três tags: a leitura da primeira encaminha o leitor para o primeiro nível do elemento (Vedaçao Vertical), a segunda para o segundo nível (Fachada), e a terceira para o terceiro nível (Fachada Frontal).
Inseridas as informações da fachada no sistema, as tags foram gravadas e fixadas na fachada frontal do edifício, junto ao hall de entrada em local iluminado e de fácil acesso ao smartphone.

O smartphone, com capacidade de leitura no padrão NFC, foi posicionado próximo às tags e realizadas as leituras. Espera-se como resultado que, ao decodificar a etiqueta, o usuário seja direcionado ao CMS, na página armazenada no sistema, que contém as informações relativas à fachada na qual a tag RFID foi instalada.

\section{Resultados e discussões}

O principal objetivo pretendido com o sistema desenvolvido foi a disponibilização das informações de manutenção a todos os usuários registrados de forma rápida, fácil e transparente. Isso ficou evidenciado nos testes realizados. As informações desejadas podem ser obtidas através da leitura das tags ou diretamente através do sistema. Os resultados das leituras das tags estão na Figura 8.

Figura 7 - Captura de tela de montagem do relatório de acompanhamento dos serviços de manutenção realizados

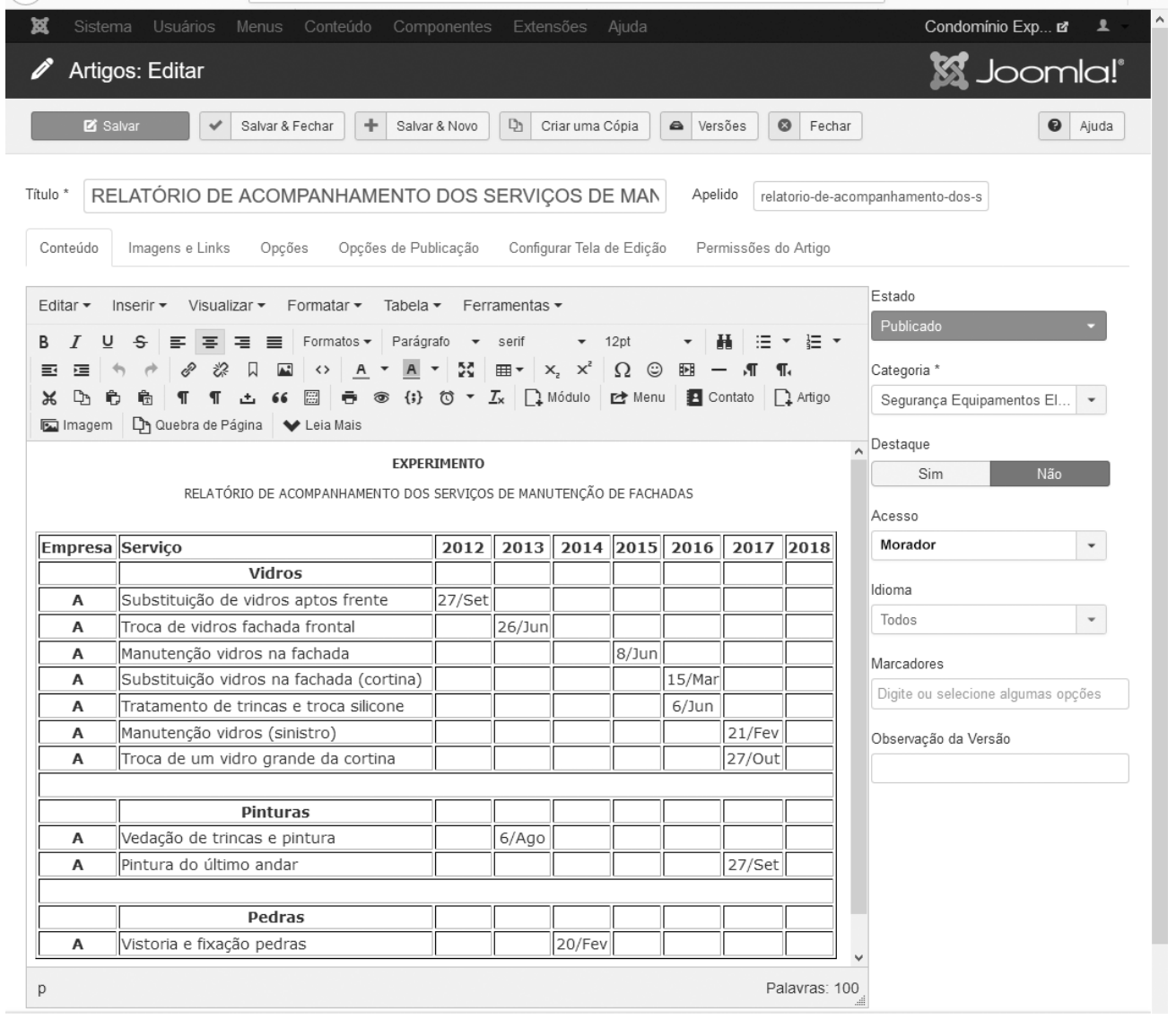


Figura 8 - Resultado das leituras das tags

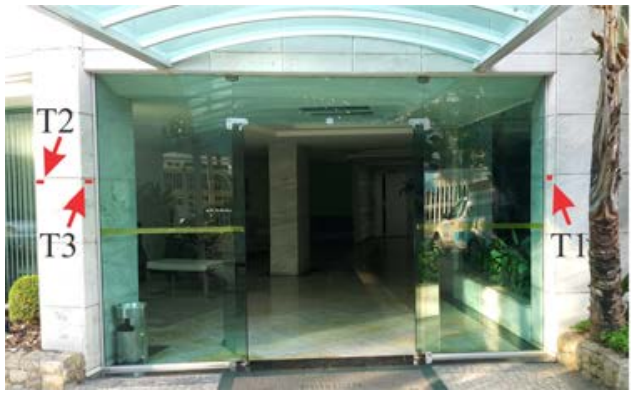

(a)

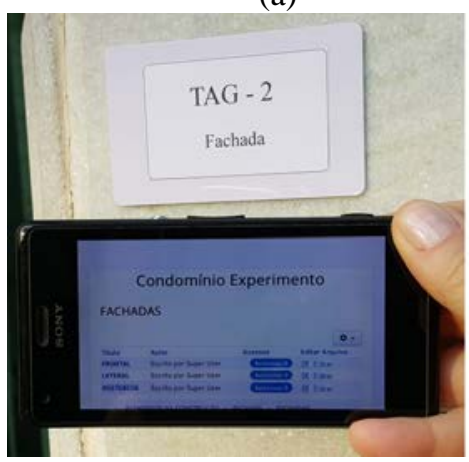

(d)

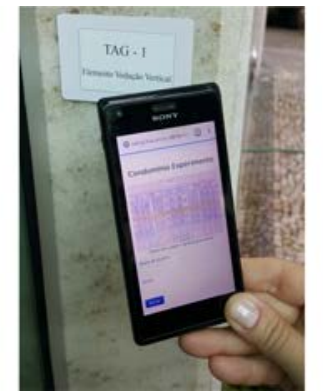

(b)

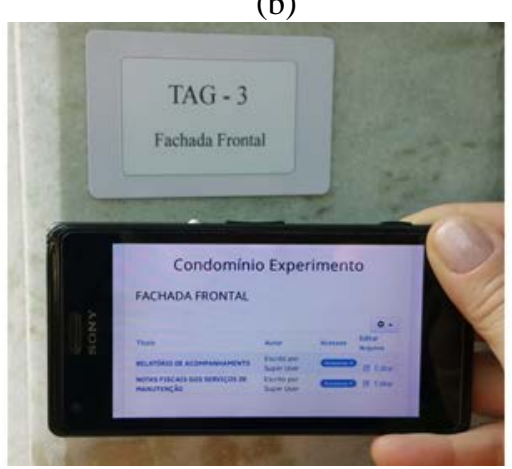

(e)

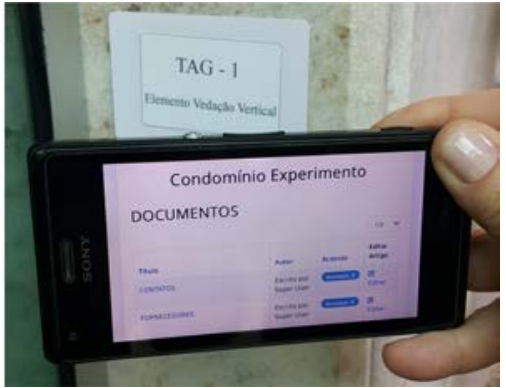

(c)

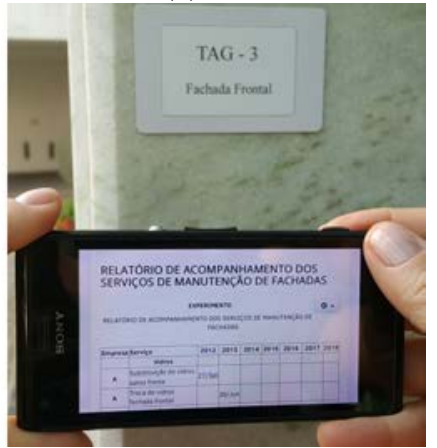

(f)
A Figura 8a apresenta a localização das tags na entrada da edificação. A primeira leitura encaminhou o leitor à página inicial do sistema, em que é solicitado login e senha (Figura 8b), a fim de ser feita a identificação do usuário. A partir daí as leituras foram capazes de direcionar o usuário à informação previamente definida na configuração do sistema. A leitura da tag 1 levou o usuário à página contendo os títulos referente ao elemento vedação vertical (Figura 8c). Nela, o usuário escolhe qual elemento quer visualizar, por exemplo, fachada.

Na leitura da tag 2 o usuário é levado à página da fachada e também pode escolher qual delas queira visualizar, por exemplo, fachada frontal (Figura 8d).

Por último, na tag 3 o usuário é direcionado diretamente à informação referente à fachada frontal. Nessa página o usuário tem a opção de visualizar as notas fiscais ou o relatório de acompanhamento dos serviços de manutenção (Figura 8e).

A Figura 8a apresenta a localização das tags na entrada da edificação. A primeira leitura encaminhou o leitor à página inicial do sistema, em que é solicitado login e senha (Figura 8b), a fim de ser feita a identificação do usuário. A partir daí as leituras foram capazes de direcionar o usuário à informação previamente definida na configuração do sistema. A leitura da tag 1 levou o usuário à página contendo os títulos referente ao elemento vedação vertical (Figura 8c). Nela, o usuário escolhe qual elemento quer visualizar, por exemplo, fachada.

Na leitura da tag 2 o usuário é levado à página da fachada e também pode escolher qual delas queira visualizar, por exemplo, fachada frontal (Figura 8d).

Por último, na tag 3 o usuário é direcionado diretamente à informação referente à fachada frontal. Nessa página o usuário tem a opção de visualizar as notas fiscais ou o relatório de acompanhamento dos serviços de manutenção (Figura 8e).

Se optar por visualizar o relatório, basta clicar sobre o título dele e será exibido o relatório de acompanhamento dos serviços de manutenção de fachadas realizados na fachada frontal (Figura 8f). A gravação das três tags permitiu demonstrar que o nível de informação a ser obtido refere-se àquele definido quando da configuração do sistema, isto é, se no nível geral ou se no nível específico.

Outra forma de obtenção das informações é através do acesso direto ao sistema a partir do endereço de domínio registrado para a identificação do servidor (Figura 9). Ao acessá-lo, o usuário é encaminhado à página inicial que solicita login e senha (Figura 8b), e a seguir para a página Documentos (Figura 9a). Nessa página, o usuário pode percorrer os vários títulos de documentos listados, ou ir ao menu presente no lado direito da página para acessar os registros ou elementos da construção. 
Figura 9 - Busca de informações através do sistema

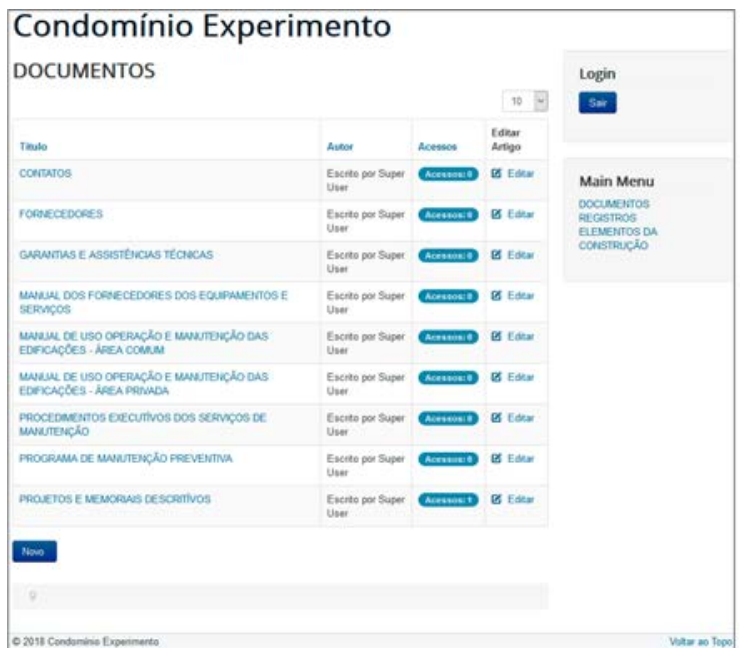

(a)

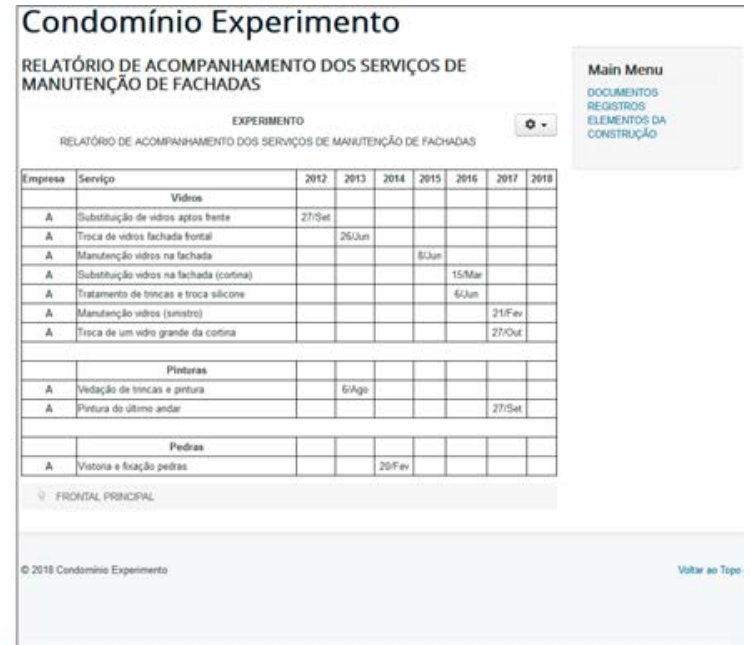

(b)
Se, por exemplo, optar por escolher visualizar os registros de manutenção da fachada frontal, é possível navegar pelas páginas de fachada (Figura 8d) e fachada frontal (Figura 8e), e clicando no título Relatório, conseguirá visualizar o relatório de acompanhamento dos serviços de manutenção de fachadas realizados na fachada frontal (Figura 9b). Esse é o mesmo conteúdo exibido no smartphone conforme a Figura 8f. O mesmo procedimento pode ser feito com relação às notas fiscais. Em função de suas dimensões, sua visualização através do sistema fica mais nítida do que através do smartphone.

O sistema permite a inclusão de qualquer tipo de informação, seja documento ou registro. Daí o primeiro passo para a implantação do sistema refere-se à definição de quais informações deverão ser consideradas.

Para a realização do experimento, foram consideradas as informações referentes aos serviços de manutenção realizados na fachada. Para a manutenção do sistema o administrador pode editar os títulos, como, por exemplo, para incluir mais colunas no relatório (Figura 7) à medida que ocorram novas intervenções na fachada. Pode também incluir novos arquivos, bastando para isso fazer o upload deles para o servidor do sistema.

Cabe destacar que, para a realização do experimento, foram utilizados somente alguns registros dos serviços de manutenção e, conforme apontado na revisão bibliográfica, vários documentos são também necessários para a realização de uma adequada manutenção da edificação. Portanto, não se pretendeu alimentar todo o conteúdo de informação no sistema, mas somente a parte necessária para mostrar a aplicabilidade do modelo aos objetivos pretendidos.
Quanto à estrutura do sistema, verifica-se que os equipamentos utilizados estão relacionados aos softwares escolhidos e à quantidade de informação a ser armazenada. Já quanto aos softwares, a opção escolhida atendeu aos propósitos do trabalho. Porém, existem no mercado outras opções de softwares livres que poderiam ser utilizadas a critério do profissional responsável por configurar e administrar o sistema. Para os usuários do sistema o procedimento para navegação não necessita treinamento, visto ser de domínio comum para acesso a endereços web.

Para as tags também existem no mercado opções mais adequadas para ser instaladas em situações expostas ao intemperismo, como as utilizadas por Oliveira e Serra (2017). Porém, as utilizadas serviram para atender aos objetivos pretendidos.

A facilidade do uso do smartphone para as leituras se mostrou evidente, bastando o operador aproximar o dispositivo da etiqueta para realizar a leitura e obter a informação desejada. Neste caso, as etiquetas precisam ser fixadas em local iluminado e de fácil acesso de maneira a permitir a aproximação do smartphone para a realização da leitura.

Dessa forma, a obtenção de informações corretas e de forma rápida foi o grande benefício obtido com o uso do modelo. Além disso, foi possível a obtenção de um histórico dos serviços de manutenção realizados, o que confirma os benefícios apontados na bibliografia. Outro benefício a ser destacado refere-se ao uso de softwares livres. Eles permitiriam reduzir o investimento necessário para a realização da tarefa de acompanhamento dos serviços de manutenção, o que democratiza o acesso às informações. 


\section{Considerações finais}

O tema manutenção de edifícios tem crescido de importância, superando a cultura de que o processo de construção termina com a obra. No Brasil a norma de desempenho NBR 15575 tem impulsionado essa discussão. A norma estabelece uma série de necessidades dos usuários a serem atendidas, o que inclui a manutenção. Nas edificações a responsabilidade pela manutenção das áreas comuns é do síndico (ou empresa contratada), que deve registrar as informações sobre os serviços de manutenção de maneira a comprovar sua realização.

O uso das TICs vem ajudar na organização dessas informações. Nesse sentido cabe destacar a tecnologia RFID, cuja aplicação tem sido discutida nas várias fases que compõem o empreendimento de construção civil.

Este trabalho apresentou um modelo de sistema para organização da informação a ser utilizado na fase de manutenção da edificação utilizando RFID e softwares de código aberto. O modelo tem por finalidade facilitar o acesso às informações de manutenção da edificação.

Os testes realizados em uma situação real serviram para demonstrar a facilidade de acesso às informações a partir da leitura das tags, bem como através do acesso ao sistema. O próprio CMS utilizado, após configurado, ajusta o leiaute para que as informações possam ser visualizadas no computador ou no smartphone. $\mathrm{O}$ uso deste para a realização das leituras simplificou o processo, visto que essa tecnologia, de maneira geral, já está dominada. Além disso, os testes também conseguiram demonstrar a aplicabilidade dos softwares livres para a realização da tarefa.

A organização das informações em um mesmo ambiente permitiu a construção de um histórico dos acontecimentos, facilitando o resgate das informações e contribuindo, dessa forma, para o processo de tomada de decisão. Permitiu também maior transparência ao processo, visto que as informações podem ser acessadas por todos aqueles que têm autorização para visualizá-las.

Uma característica do modelo refere-se ao fato de ele ter sido desenvolvido com os elementos básicos do framework/CMS adotado. Porém, recursos mais avançados podem ser agregados ao sistema mediante a instalação de extensões em forma de módulos, plugins, componentes e templates. Assim, vê-se como trabalho futuro a pesquisa de extensões de elementos avançados que permitam a inclusão de novas funcionalidades, como a criação de formulários para sugestões e reclamações dos moradores. Outra opção é a implantação de solicitações de reparos (acompanhadas de fotos) das áreas comuns da edificação a serem encaminhadas diretamente ao síndico e mesmo para a realização de inspeções.

Em outra direção vê-se a possibilidade de integração do modelo à plataforma BIM, para o caso de edificações tanto novas quanto antigas. Para o primeiro caso, os projetistas desenvolveriam seus projetos usando objetos contendo as informações de manutenção, o que iria colaborar para a criação de documentos de manutenção, facilitando, dessa forma, a realização das atividades. Para as edificações construídas antes da utilização do BIM, seria necessária a modelagem da edificação, para posteriormente serem inseridas as informações de manutenção.

\section{Referências}

ALTAF et al. Integrated Production Planning and Control System for a Panelized Home

Prefabrication Facility Using Simulation and RFID. Automation in Construction, v. 85, p. 369-383, 2018.

ANUMBA, C. J.; EGBU, C.; CARRILO, P. M. Knowledge Management in Construction. New Jersey: Wiley-Blackwell, 2005.

ASSOCIAÇÃO BRASILEIRA DE NORMAS TÉCNICAS. NBR 14037: diretrizes para elaboração de manuais de uso, operação e manutenção de edificações: requisitos para elaboração e apresentação dos conteúdos. Rio de Janeiro, 2011.

\section{ASSOCIAÇÃO BRASILEIRA DE NORMAS}

TÉCNICAS. NBR 5674: manutenção de edificações: requisitos para o sistema de gestão de manutenção. Rio de Janeiro, 2012.

\section{ASSOCIAÇÃO BRASILEIRA DE NORMAS TÉCNICAS. NBR 15575: edificações} habitacionais: desempenho. Rio de Janeiro, 2013.

AU-YONG, C. P.; ALI, A. S.; AHMAD, F. Improving Occupants' Satisfaction with Effective Maintenance Management of HVAC System in Office Buildings. Automation in Construction, v. 43, p. 31-37, 2014.

BRASIL. Decreto ${ }^{0}$ 9.377, de 17 de maio de 2018, que institui a Estratégia Nacional de Disseminação do Building Information Modelling. Diário Oficial da União, Brasília, 17 de maio de 2018.

CHEN, M. et al. Proactive 2D Model-Based Scan Planning for Existing Buildings. Automation in Construction, v. 93, p. 165-177, 2018. 
CINTRA, M. A. H. Uma Proposta de Estrutura para Organização do Conhecimento na Pequena Empresa de Edificações. Rio de Janeiro, 2005. Tese (Doutorado em Engenharia de Produção) - Universidade Federal do Rio de Janeiro, Rio de Janeiro, 2005.

COSTIN, A.; PRADHANANGA, N.; TEIZER, J. Leveraging Passive RFID Technology for Construction Resource Field Mobility and Status Monitoring in a High-Rise Renovation Project. Automation in Construction, v. 24, p. 1-15, 2012.

DEMIRALP, G.; GUVEN, G.; ERGEN, E. Analyzing the Benefits of RFID Technology for Cost Sharing in Construction Supply Chains: a case study on prefabricated precast components. Automation in Construction, v. 24, p. 120-129, 2012.

DRESCH, A.; LACERDA, D. P.; ANTUNES JINIOR, J. A. V. Design Science Research: a method for science and technology advancement. Cham: Springer International Publishing Switzerland, 2015.

DZENG, R.; LIN, C.; HSIAO, F. Application of RFID Tracking to the Optimization of FunctionSpace Assignment in Buildings. Automation in Construction, v. 40, p. 68-83, 2014.

EASTMAN, C. et al. BIM Handbook: a guide to building information modelling for owners, managers, designers, engineers and contractors. $2^{\text {nd }}$. ed. New York: John Wiley \& Sons, 2011.

EL-HARAM, M. A.; HORNER, M. W. Factors Affecting Housing Maintenance Cost. Journal of Quality in Maintenance Engineering, v. 8, n. 2, p. 115-123, 2002.

EL-OMARI, S; MOSELHI, O. Integrating Automated Data Acquisition Technologies For Progress Reporting of Construction Projects. Automation in Construction, v. 20, p. 699-705, 2011.

ERGEN, E. et al. Tracking Components and Maintenance History Within a Facility Utilizing Radio Frequency Identification Technology. Journal of Computing in Civil Engineering, v. 21, n. 1, p. 11-20, 2007.

FERREIRA, F. P. Gestão de facilities: estudo exploratório da prática em empresas instaladas na região metropolitana de Porto Alegre. Porto Alegre, 2005. Dissertação (Mestrado em Engenharia Civil) - Escola de Engenharia, Universidade Federal do Rio Grande do Sul, Porto Alegre, 2005.
GNIPPER, S. F. Diretrizes Para Formulação de Método Hierarquizado Para Investigação de Patologias em Sistemas Prediais Hidráulicos e Sanitários. São Paulo, 2010. Dissertação (Mestrado em Engenharia Civil) - Escola de Engenharia, Universidade Estadual de Campinas, São Paulo, 2010.

GONÇALVES, C. D. F. Gestão da Manutenção em Edifícios: modelos para uma abordagem LARG (Lean, Agile, Resilient e Green). Lisboa, 2014. Tese (Doutorado em Engenharia Industrial) - Faculdade Nova de Lisboa, Lisboa, 2014.

HINKKA, V.; TÄTILÄ, J. RFID Tracking Implementation Model for the Technical Trade and Construction Supply Chains. Automation in Construction, v. 35, p. 405-414, 2013.

INTERNATIONAL ORGANIZATION FOR STANDARDIZATION. ISO/IEC 18092:

information technology: telecommunications and information exchange between systems: Near Field Communication: Interface and Protocol (NFCIP1). Bruxels, 2013.

KATZ, A. Authors and Owners. In: ABEL, B. et al. (Ed.). Open Design Now. Amsterdam: BIS Publishers, 2011.

KELM, A. et al. Mobile Passive Radio Frequency Identification (RFID) Portal for Automated and Rapid Control of Personal Protective Equipment (PPE) on Construction Sites. Automation in Construction, v. 36, p.38-52, 2013.

KIM, S. S. et al. Development of a Housing Performance Evaluation Model For Multi-Family Residential Buildings in Korea. Building and Environment, v. 40, p. 1103-1116, 2005.

KLEIN, A.; LI, N.; BECERIK-GERBER, B. Imaged-Based Verification of As-Built Documentation of Operational Buildings. Automation in Construction, v. 21, p. 161-171, 2012.

KO, C. RFID-Based Building Maintenance System. Automation in Construction, v. 18, p. 275-284, 2009.

KO, C. Accessibility of Radio Frequency Identification Technology in Facilities Maintenance. Journal of Engineering, Project, and Production Management, v. 7, n. 1, p. 4553, 2017.

KO, H.; AZAMBUJA, M.; FELIX LEE, H. CloudBased Materials Tracking System Prototype Integrated With Radio Frequency Identification Tagging Technology. Automation in Construction, v. 63, p. 144-154, 2016. 
LEE, S.; AKIN, Ö. Shadowing Tradespeople: inefficiency in maintenance fieldwork.

Automation in Construction, v. 18, p. 536-546, 2009.

LI, N.; BECERIK-GERBER, B. Life-Cycle Approach for Implementing RFID Technology in Construction: learning from academic and industry use cases. Journal of Construction Engineering and Management, v. 137, n. 12, p. 1089-1098, 2011.

LI, N.; CALIS, G.; BECERIK-GERBER, B. Measuring and Monitoring Occupancy With an RFID Based System for Demand-Driven HVAC Operations. Automation in Construction, v. 24, p. 89-100, 2012.

LI, N. et al. A BIM Centered Indoor Localization Algorithm to Support Building fire Emergency Response Operations. Automation in Construction, v. 42, p. 78-89, 2014.

LIN, Y.; CHEUNG, W.; SIAO, F. Developing Móbile 2D Barcode/RFID-Based Maintenance Management System. Automation in Construction, v. 37, p. 110-121, 2014.

LU, Q. et al. Activity Theory-Based Analysis of BIM Implementation in Building O\&M and First Response. Automation in Construction, v. 85, p. 317-332, 2018.

LU, W.; HUANG, G.Q.; LI, H. Scenarios for Applying RFID Technology in Construction Project Management. Automation in

Construction, v. 20, p. 101-106, 2011.

MELO FILHO, E. C.; RABBANIB, E. R. K.; BARKOKEBAS JUNIOR, B. Avaliação da Segurança do Trabalho em Obras de Manutenção de Edificações Verticais. Revista Produção, v. 22, n. 4, p. 817-830, 2012.

MINISTÉRIO DA ECONOMIA INDÚSTRIA, COMÉRCIO EXTERIOR E SERVIÇOS.

Governo Federal Lança Estratégia Para Promover a Inovação na Indústria da Construção. 2018. Disponível em: <http://www.mdic.gov.br/index.php/noticias/3296governo-federal-lanca-estrategia-para-promoverinovacao-na-industria-da-construcao>. Acesso em: 20 set. 2018.

MOREIRA, A. C. Diretrizes Para a Proposição de Um Modelo Lógico Baseado na Web Orientação: aplicação voltada à rastreabilidade e recuperação da informação na construção civil. Juiz de Fora, 2017. Dissertação (Mestrado em Ambiente Construído) - Faculdade de Engenharia, Universidade Federal de Juiz de Fora, Juiz de Fora, 2017.
MOTA, P. P. Modelo BIM para Gestão de Ativos. Campinas, 2017. Dissertação (Mestrado em Arquitetura, Tecnologia e Cidade) - Escola de Engenharia, Universidade Estadual de Campinas, Campinas, 2017.

MOTAWA, I.; ALMARSHAD, A. A KnowledgeBased BIM System for Building Maintenance. Automation in Construction, v. 29, p. 173-182, 2013.

OLIVEIRA, V. H. M.; SERRA, S. M. B. Controle de Obras por RFID: sistema de monitoramento e controle para equipamentos de segurança no canteiro de obras. Ambiente Construído, Porto Alegre, v. 17, n. 4, p. 61-77, out./dez. 2017.

PÄRNA, E. A.; EDWARDS, D. J.; SING, M. C. P. The Building Information Modelling Trajectory in Facilities Management: a review. Automation in Construction, v. 75, p. 45-55, 2017.

RFID Journal Brasil. Como Fazer o Rastreamento de Materiais de Construção. 2013. Disponível em: $<$ https://brasil.rfidjournal.com/reportagens/vision? 11030/6>. Acesso em: 22 nov. 2017.

SANCHES, I. D.; FABRICIO, M. M. A Importância do Projeto na Manutenção de HIS. In: SIMPÓSIO BRASILEIRO DE GESTÃO E ECONOMIA DA CONSTRUÇÃO, 6., João Pessoa, 2009. Anais... João Pessoa: Antac, 2009.

SHEN, W.; HAO, Q.; XUE, Y. A Loosely Coupled System Integration Approach for Decision Support in Facility Management and Maintenance. Automation in Construction, v. 25, p. 41-48, 2012.

TAKEDA, H. et al. Modeling Design Processes. Al Magazine, v. 11, n. 4, p. 37-48, 1990.

TAO, X. et al. Greenhouse Gas Emission Monitoring System For Manufacturing Prefabricated Components. Automation in Construction, v. 93, p. 361-374, 2018.

TOLMAN, A. et al. The Benefits and Obstacles of Mobile Technology in FM Service Procurement. Facilities, v. 27, n. 11-12, p. 445-456, 2009.

TULLA, K. et al. RFID Technology Changes FM Services Deliveries. Facilities, v. 27, n. 11-12, p. 457-468, 2009.

VALERO, E.; ADAN, A.; CERRADA, C. Evolution of RFID Applications in Construction: a literature review. Sensors, v. 15, p. 15988-16008, 2015.

VOLK, R.; STENGEL, J.; SCHULTMANN, F. Building Information Modelling (BIM) for Existing Buildings: literature review and future needs. Automation in Construction, v. 38, p. 109-127, 2014. 
XUA, Z. et al. Modeling and Problem Solving of Building Defects Using Point Clouds and Enhanced Case-Based Reasoning. Automation in Construction, v. 96, p. 40-54, 2018.

XUE, F. et al. Linking Radio-Frequency Identification to Building Information Modeling: status quo, development trajectory and guidelines for practitioners. Automation in Construction, v. 93, p. 241-251, 2018.

WANG, L. C. Enhancing Construction Quality Inspection and Management Using RFID

Technology. Automation Construction, v. 17, p. 467-479, 2008.
WONG, J. K. W.; GE, J.; HE, S. X. Digitisation in Facilities Management: a literature review and future research directions. Automation in Construction, v. 92, p. 312-326, 2018.

ZHONG, R. Y. et al. Prefabricated Construction Enabled by the Internet-of-Things. Automation in Construction, v. 76, p. 59-70, 2017.

\section{Agradecimentos}

À CAPES pela bolsa PNPD/CAPES concedida à primeira autora.

Maria Aparecida Steinherz Hippert

Departamento de Construção Civil, Faculdade de Engenharia | Universidade Federal de J uiz de Fora | 4a Plataforma, Campus

Universitário, Martelos | J uiz de Fora - MG - Brasil | CEP 36036-330 | Tel.: (32) 3229-3405 | E-mail: aparecida.hippert@ufjf.edu.br

Orlando Celso Longo

Centro Tecnológico | Universidade Federal Fluminense | Rua Passo da Patria, 156, Bloco D, Sala 360, São Domingos | Niterói - RJ - Brasil | CEP 24210-240 | Tel.: (21) 2629-5410 | E-mail: orlandolongo@gmail.com

Adriano Castro Moreira

Núcleo de Ergonomia e Sustentabilidade em Transportes, Faculdade de Engenharia | Universidade Federal de J uiz de Fora | E-mail: adriano.castro@engenharia.ufjf.br

\section{Revista Ambiente Construído}

Associação Nacional de Tecnologia do Ambiente Construído

Av. Osvaldo Aranha, 99 - 30 andar, Centro

Porto Alegre - RS - Brasil

CEP $90035-190$

Telefone: +55 (51) 3308-4084

Fax: +55 (51) 3308-4054

www. seer. ufrgs. br/ ambienteconstruido

E-mail: ambienteconstruido@ufrgs.br

(c) (i) This is an open-access article distributed under the terms of the Creative Commons Attribution License. 


\section{Errata}

No artigo "RFID na edificação: proposta de modelo de sistema para organização das informações de manutenção", com número de DOI: <http://dx.doi.org/10.1590/s1678-86212019000400348>, publicado no periódico Ambiente Construído, 19(4):155-173.

Na página 173:

Leia-se:

"Agradecimentos

À CAPES pela bolsa PNPD/CAPES concedida à primeira autora.” 